\title{
Endoscopic Surgery of Third Ventricular Lesions
}

\author{
AHMED A. ABDELKHALEK, M.D. and MOHAMED A. THABIT, M.D. \\ The Department of Neurosurgery, Faculty of Medicine, Cairo University
}

\begin{abstract}
Background: The endoscopic surgery to third ventricular lesions are now widely used as it is less invasive than the traditional microsurgical procedures.
\end{abstract}

Aim of Study: To evaluate endoscopic surgery of third ventricular lesions as regards clinical improvement, complication rate and extent of lesion resection.

Patients and Methods: Retrospectively eleven cases of third ventricular lesions (seven cases of colloid cyst, two cases of astrocytoma, one case epidermoid cyst and 1 case of arachnoid cyst) were operated upon through endoscopic route for total excision if feasible, pre-operative assessment in the form of full neurological examination and imaging (CT and MRI) were done for all patients. Incompletely removed lesions were managed by a septostomy and VP shunt, post-operatively CT was performed in the first 24 hours after surgery and another after 48 hours, MRI with contrast was done 6 months post-operatively to detect recurrence, patients with persistent post-operative hydrocephalus had VP shunt insertion.

Results: Complete resection was achieved in nine patients $(82 \%)$, while resection was incomplete in two cases $(18 \%)$. complications were in one case $(9 \%)$ in the form of short memory affection improved after one month, post-operative hydrocephalus was in one patient (9\%), mean length of hospital stay was three and half days, no recurrence was reported in all patients with complete resection for a follow-up period of 12 months.

Conclusion: Endoscopic resection of third ventricular lesions is safe, minimally invasive, technically feasible and with good outcome especially in completely removed lesions.

Key Words: Endoscopic surgery - Third ventricular tumors - Hydrocephalus - ETV.

\section{Introduction}

TUMORS involving the third ventricle are not common with low incidence of the total brain tumors which is about 0.6 to 0.9 percent [1-4]. The most common tumor involving the third ventricle in adults is the colloid cyst followed by ependymomas and choroid plexus tumors in children,

Correspondence to: Dr. Ahmed A. Abdelkhalek, The Department of Neurosurgery, Faculty of Medicine, Cairo University other rare pathologies are craniopharyngioma, optic gliomas, pineal region masses and thalamic masses [1-3]. Lesions of the third ventricle are classified according to their location relative to the foramen of Monro into anterior posterior and whole third venricular lesions, this division is based on their position in relation to the foramen of Monro so that anterior lesions are in front of the foramen of Monro and posterior lesions are behind the foramen of Monro [3-6]. Below five years of age choroid plexus tumors and ependymomas are the predominant pathologies, while in adults colloid cyst is the main pathology and is usually located at the anterior third ventricle [3-6]. There are no definite symptoms defining intravenricular tumors but the most common presenting symptom is headache and other increased tension manifestations due to secondary hydrocephalus [4-6]. The third ventricle is located deeply inside the brain tissue with a complex anatomy of its walls formed by very important structures namely the hypothalamus, the thalamus, the fornix and the optic chiasm, thus this makes surgical approaches and techniques for that region a bit tricky and difficult with a huge challenge for the neurosurgeon [6-8]. The third ventricle is either approached via a transcortical or a transcallosal route either anteriorly or posteriorly with both routes having its merits and disadvantages, but actually the approach itself adds to the morbidity of the overall procedure and sometimes the mortality rate also is a little bit increased $[7,8]$. So the surgical procedure is risky and difficult regarding both the approach and the surgery itself but after the evolution of intraventricular endoscopic procedure and the progressive developing technological enhancements to the scopes and the instruments it made it easier and safer to approach and remove third ventricular masses, this decreased the morbidity for the surgery and also the possibility of addressing the problem of associated hydrocephalus made it a better way to perform intraventricular surgeries. That is why recently endoscopic proce- 
dures gained more popularity for intravenricular lesions [7-9].

\section{Patients and Methods}

Eleven consecutive patients with strictly third ventricular masses with or without hydrocephalus with any age and gender were included. All patients were operated at Cairo University Hospitals from January 2016 till November 2017. All patients were assessed pre-operatively by taking full history, neurological examination, pre-operative scanning with CT scan and MRI scans. All patients undergone endoscopic surgery for their lesions, patients were positioned supine, head extended, aright sided burr-hole situated a little bit anterior farther than the standard Kokher burr-hole (2-3 centimeters anterior) which helps us to navigate more posterior if needed and also inspection of posterior third ventricle, the head is fixed in 3 pin skull clamp and mayfield fixator, a u shaped skin flap is used with the possibility of further extension if a bone flap is needed to be done for the possibility of microscopic surgery to be done at any point, the burr hole is done, dura coagulated with the bipolar, dural incision with a scalpel, corticectomy is done, the ventricle is inspected with the 0 degree diagnostic scope first the choroid plexus is followed to the foramen of Monro, the foramen is inspected for the lesion, the lesion is then addressed according to its nature (e.g. in cases of colloid cysts the cyst wall is coagulated the contents are evacuated then the walls are dissected away from the ventricular wall and the choroid plexus, then an ETV is done or a shunt inserted). After removal of the lesion an attempt of ETV for hydrocephalus relief is performed if the lesion is not removed completely a septostomy is done and a VP shunt is inserted. Hemo stasis is achieved inspection of the ventricle for any residual tumor or points of bleeding, ample lavage and then closure is done. A follow-up CT scan is done at the first 24 hours, ICU monitoring of the patient, and follow-up of the neurological status. A follow-up MRI with contrast is done after three months and then every six months for two years then yearly for 3 years.

\section{Results}

Eleven patients were included in the study, five males and six females, age ranged from 18 to 48 years, the pathological lesions were seven cases of colloid cyst, two cases of astrocytoma, one case epidermoid cyst and 1 case of arachnoid cyst, radical removal was achieved in nine lesions $(82 \%)$ while two cases of incomplete removal both were astrocytoma (18\%). No complications were reported except in one patient who had short term memory loss due to fornicial injury (a case with colloid cyst) which was only temporary lasted for less than one month while another patient had persistent postoperative HCP despite that we performed an ETV intraoperatively. The most common presentation was headache and blurring of vision, preoperative HCP was present in nine patients and three patients had VP shunt insertion two intraoperative (incompletely removed gliomas) and one post-operative (the epidermoid patient). The mean length of stay at the hospital was three and half days, no recurrence was reported in all patients with complete resection for a follow-up period of twelve months.

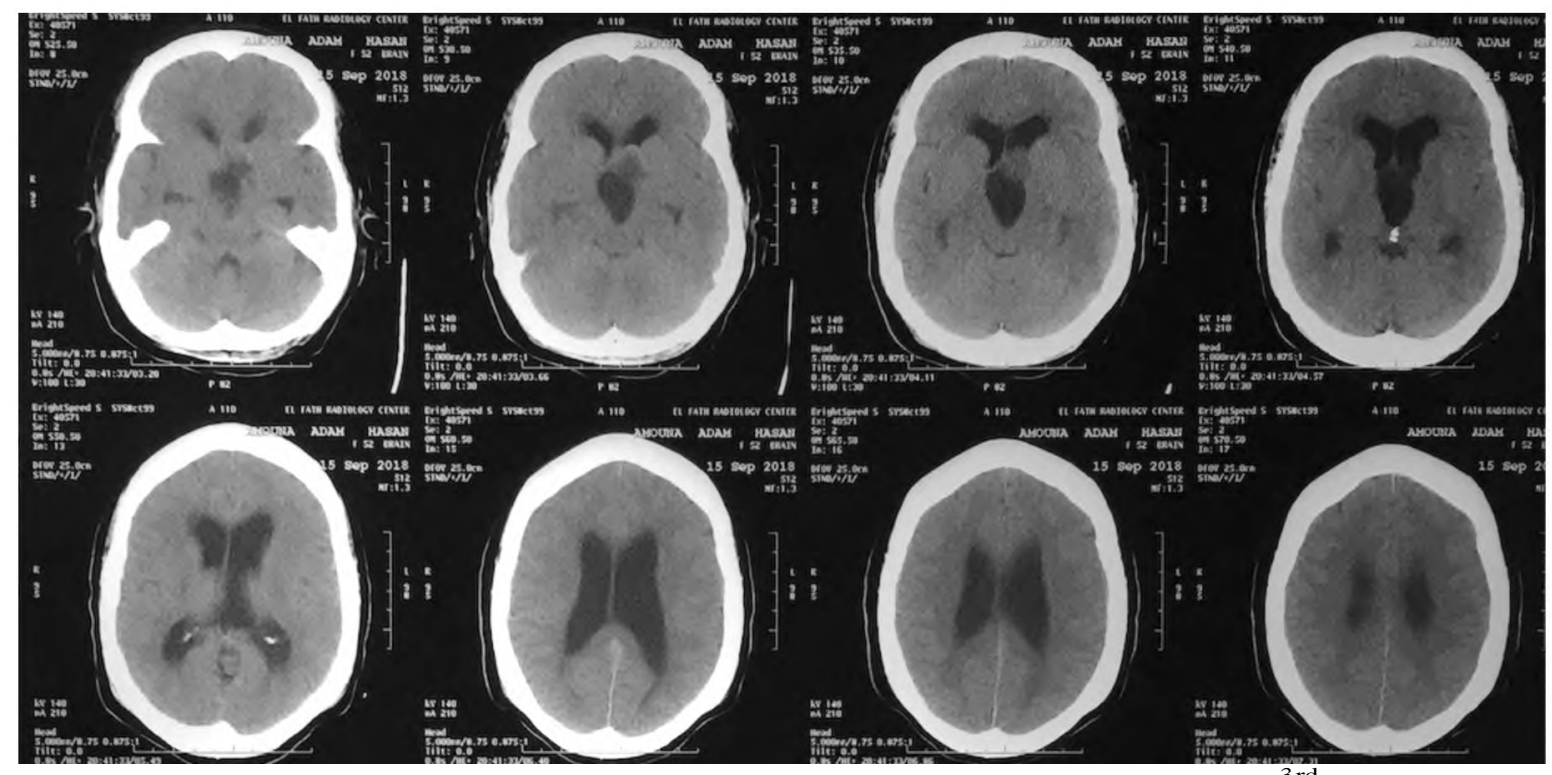

Fig. (1): Pre-operative CT of a 48 years old lady with increased tension manifestations scans showed ${ }^{3 \text { rd }}$ ventricular mass with HCP, MRI showed different enhancement lesion, intraoperative it was an epidermoid with adherent choroid plexus (hence the enhancement), post-operative patient had HCP and a VP shunt was inserted. 

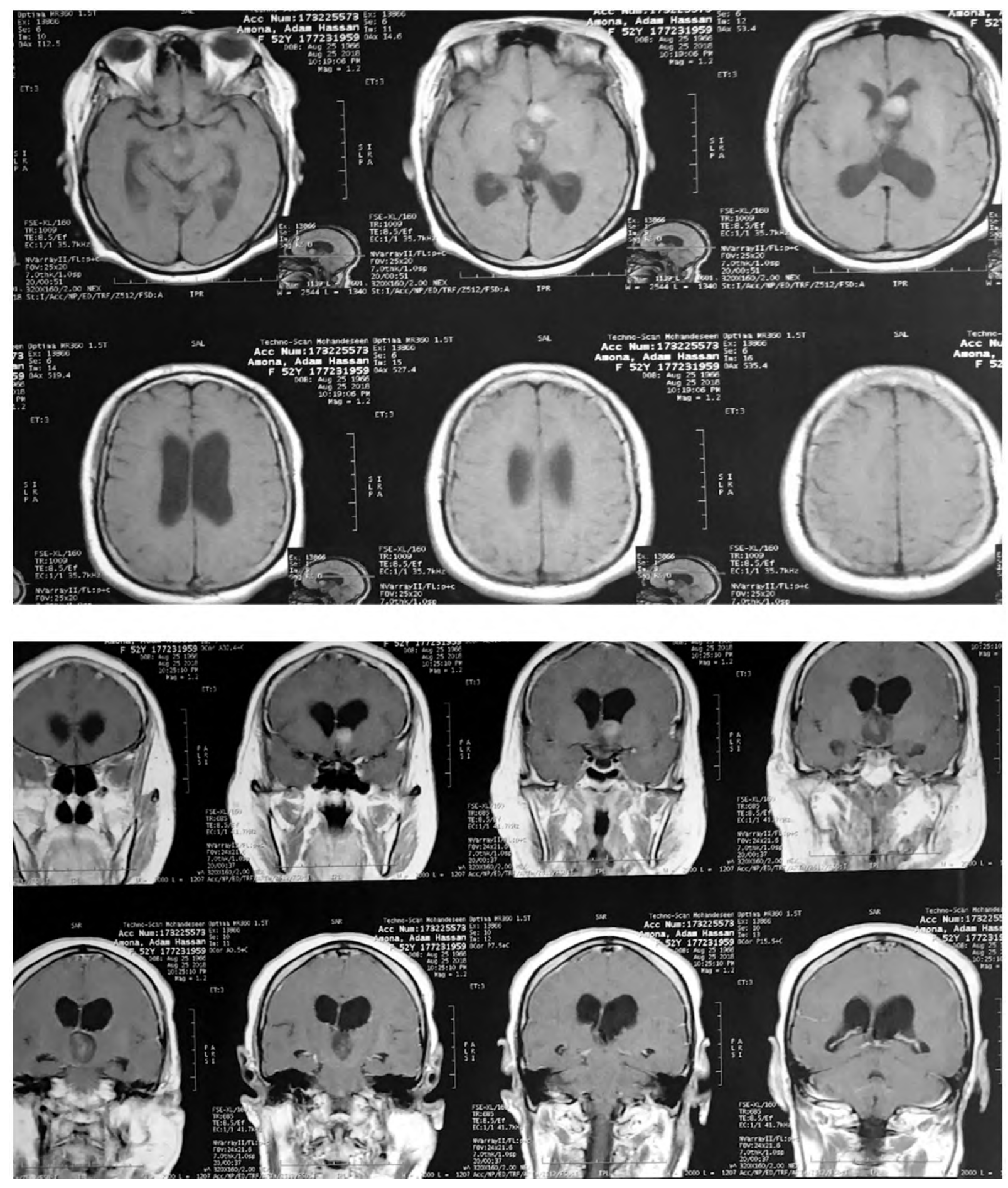

Fig. (2): Pre-operative MRI. 


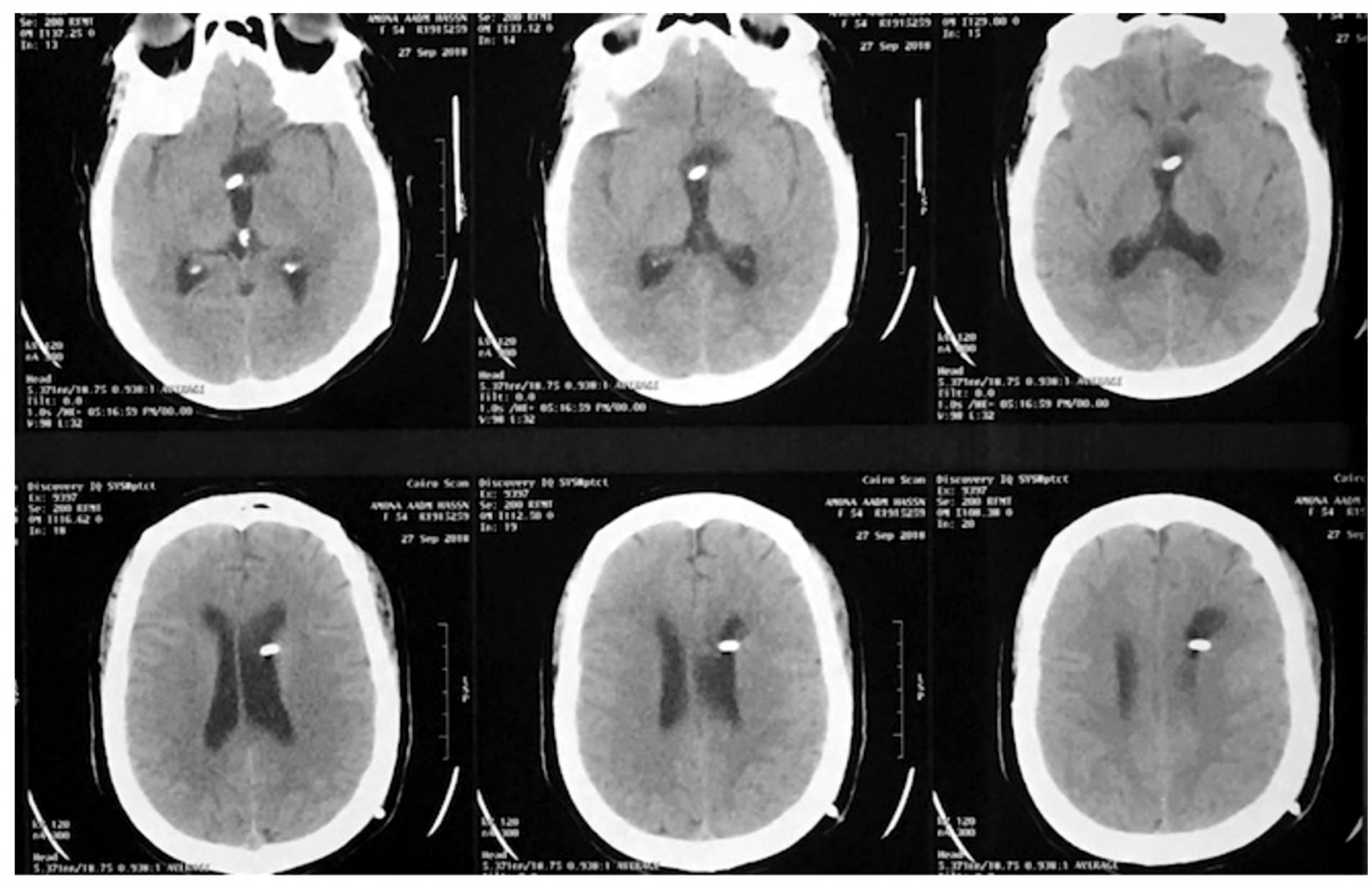

Fig. (3): Post-operative CT.

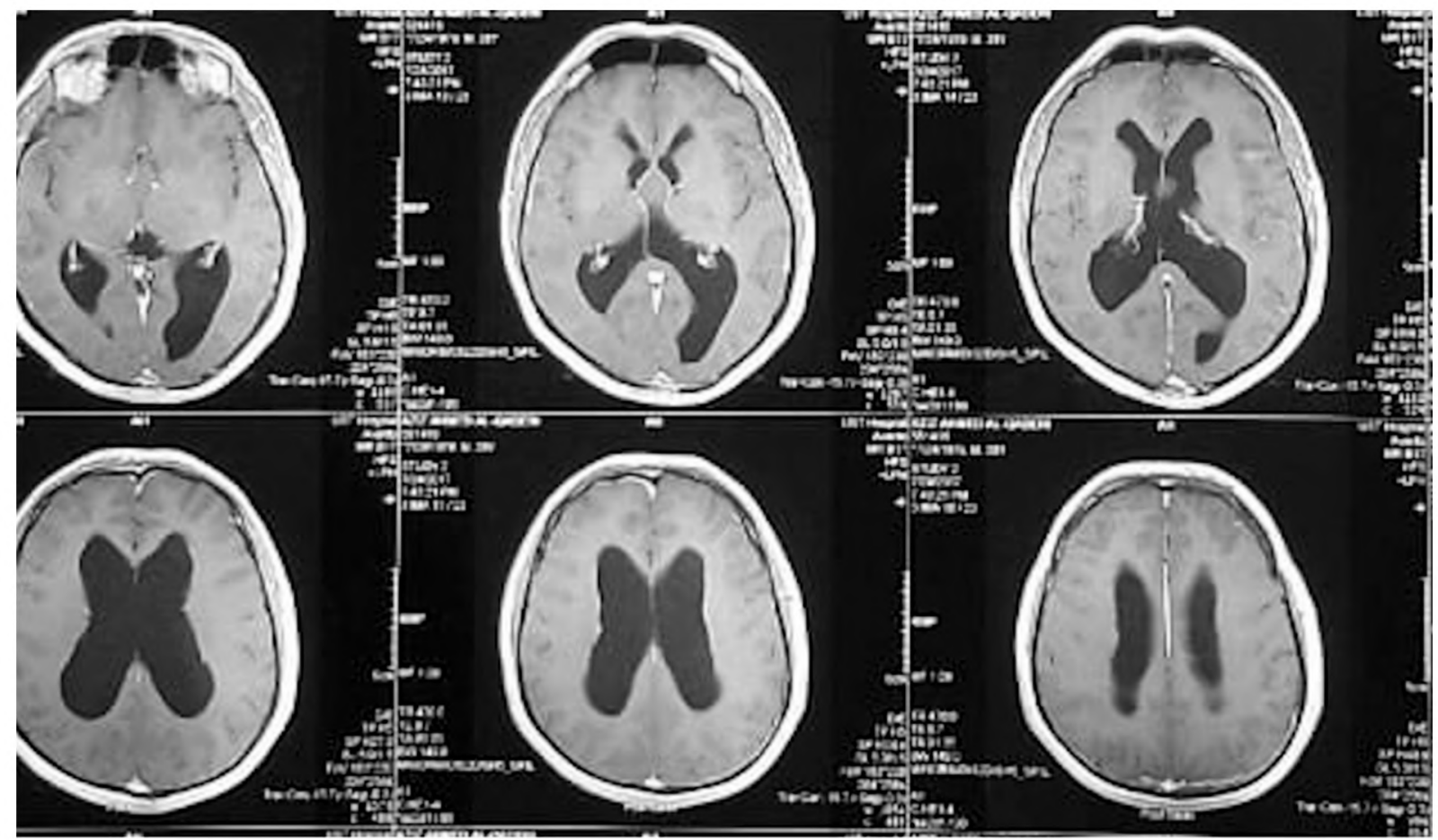

Fig. (4): Pre-operative MRI of a 28 years old male with colloid cyst with no HCP done endoscopically and didn't need any further intervention post-operative, patient had short term memory deficit resolved after one month. 

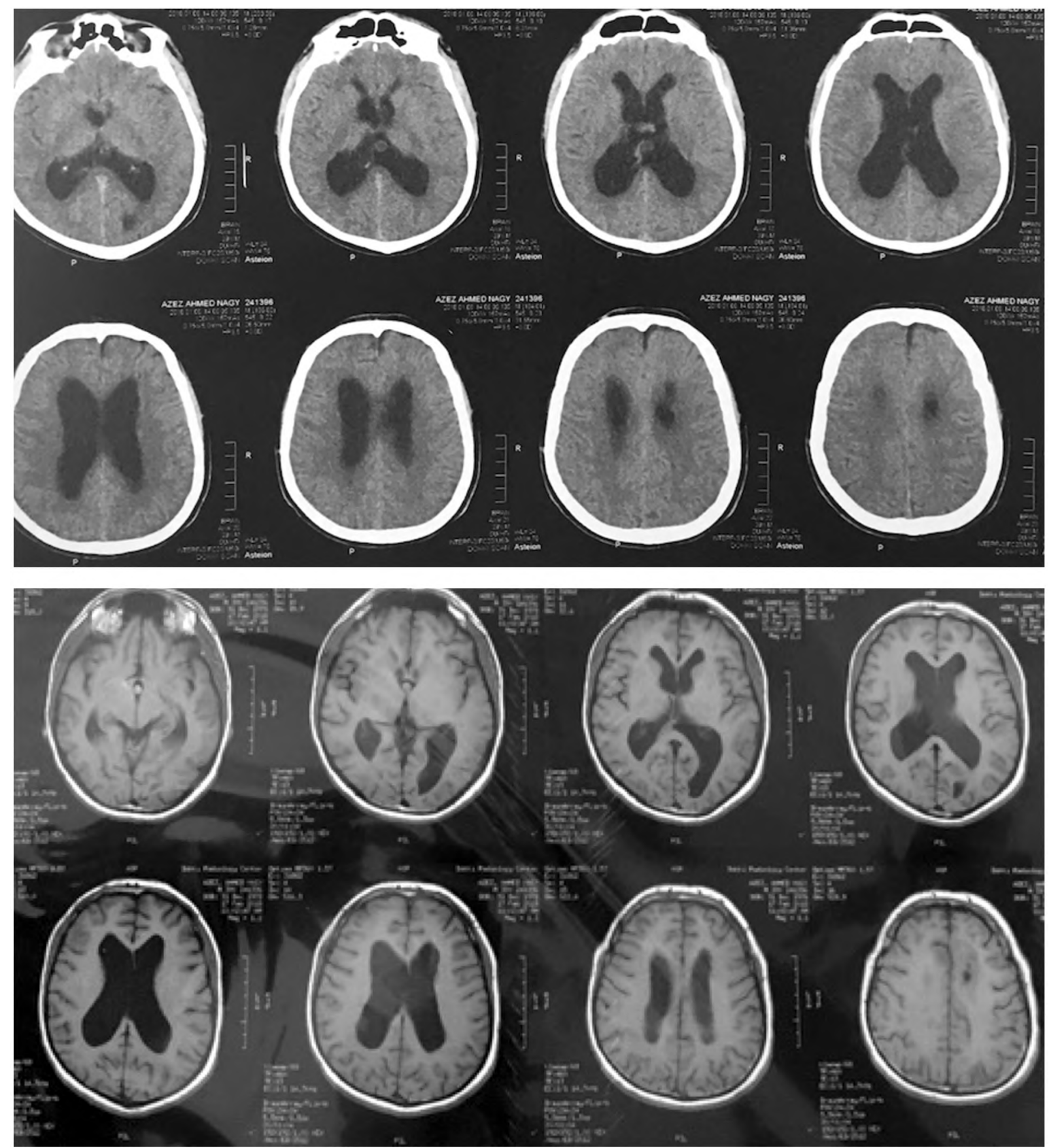

Fig. (5): Post-operative CT and MRI.

\section{Discussion}

In our study, we had 11 cases 7 colloid cysts, 2 astrocytoma, one epidermoid and one case of arachnoid cyst with complication rate in 2 patients (18\%), the mean hospital stay was 3.5 days. We also have done ETV in nine 8 cases and septostomy plus VP shunt in 2 cases while VP shunt in one patient, removal rate was total in $82 \%$ of cases with no recurrence in totally removed cases. Lewis et al., [10] operated 7 cases all were colloid cysts with pre-operative HCP in five cases they didn't do any other adjunctive procedures with total removal rate of $100 \%$ with only one complicated patient and recurrence in one case. Abdou and Cohen [3] operated 13 cases all were colloid cysts all had HCP preoperative with no complications nor any adjunctive procedure and their radical removal rate was $76.9 \%$ with $0 \%$ recurrence. Gaab and Schroeder [11] operated 19 cases 7 colloid cysts, 3 subependymoma, 2 low grade gliomas, one germinoma, one pineal cyst, one epidermoid, 
one hemangioma, one cavernoma, one choroid plexus papilloma and one ependymoma, the did ETV for two cases, septostomy for one case and aqueduct stent for 2 cases, they had rate of total removal of $68.4 \%$ with complications in only 3 cases and recurrence in one patient. King et al., [12] operated 13 cases of colloid cysts with preoperative HCP in 12 patients, they performed septostomy in the whole series, the mean hospital stay was 2.3 days, rate of total removal was $83.3 \%$ with 2 complicated cases and no recurrence. Rodziewicz et al., [13] operated 12 cases of colloid cyst with HCP in 6 cases also doing septostomy for all patients and had total removal in $91 \%$ of cases with one complicated case and one case of recurrence. Decq et al., [14] also had a series of colloid cyst cases [22] with preoperative HCP in 21 cases, they didn't perform any adjuvant surgery and had no recurrence nor complications with rate of total removal of $63.6 \%$. Kehler et al., [8] also had 10 cases of colloid cysts with total removal rate of $90 \%$, one recurrence and complications in 3 cases. Hellwig et al., [15] operated 20 patients with colloid cysts with pre-operative HCP in 19 patients, the mean hospital stay was seven days, the radical resection was $81 \%$, with one recurrence and 4 complicated cases. Husain et al., [16] operated 25 patients, 11 colloid cysts, 2 ependymomas, 2 choroid plexus tumors, 2 septum pellucidum cysts, 2 arachnoid cyst and others, radicality was $80 \%$, with 3 complicated cases. Longatti et al., [17] had 61 patients with colloid cysts in their series with 53 patients with HCP pre-operatively, 7 patients had ETV done with radical rate of $57.7 \%, 32$ complications and 24 recurrences. Souweidane and Luther [18] had 7 cases in their series 2 ependymomas, neurocytomas and gliomas plus one subependymoma, all had HCP with hospital stay of 2.6 days, 2 complicated cases, radicality of $71.4 \%$ and no recurrences. Lekovic et al., [19] operated 2 cases with hypothalamic hamartomas, with $50 \%$ radicality, no complications nor recurrence. Grondin et al., [2] operated 25 colloid cysts, 22 had HCP, with mean hospital stay of 3.8 days, 3 complicated cases, $96 \%$ radical removal and 1 recurrence. Horn et al., [20] operated 28 colloid cysts, 17 of them had HCP pre-operative, the mean hospital stay was 5.4 days, with radical resection rate of $52.6 \%$, three complicated cases and no recurrence. Levine et al., [21] had 35 colloid cases in their series with $91.4 \%$ radicality, 7 complicated cases and 7 recurrences. Greenlee et al., [22] had 35 cases of colloid cysts with mean hospital stay of 3 days, three complicated cases, total removal rate was $82.8 \%$ and one recurrent case. El-Ghandour et al., [23] had 10 cases of colloid cysts with all patients had
HCP, did 2 ETV, total removal was $80 \%$ with one complicated case and no recurrence. Oertel et al., [24] had 11 cases in their series, did ETV for all cases had radical removal rate of $36.3 \%$ and 7 complicated cases. Mishra et al., [25] operated 59 colloid cysts, all had HCP, with 19 complicated cases and radical removal of $89.8 \%$. Najjar et al., [26] operated 7 cases 3 were colloid cysts, 6 had $\mathrm{HCP}, \mathrm{ETV}$ done in one case and septostomy in 2 others, with removal rate of $57.1 \%$. Boogaarts et al., [27] had 90 colloid cysts in their series, did ETV for 7, 32 complications and total removal rate of $57.5 \%$ with 24 recurrent cases. Naftel et al., [28] operated on 4 patients 2 colloid cysts and 2 hypothalamic hamartomas with one patient having $\mathrm{HCP}$, no reported complications and radicality rate of $75 \%$. Dlouhy et al., [29] had 4 patients in their series 3 colloid cysts and one pineoblastoma with total removal $100 \%$. Delitala et al., [30] operated 7 cases of colloid cysts with 4 patients with HCP with radical rate of $85.7 \%$. Wilson et al., [31] operated 22 cases of colloid cysts, 19 of them had $\mathrm{HCP}$, and the rate of total removal was $95.4 \%$. Margetis and Souweidane [32] operated 67 patients with colloid cysts, had 4 complicated cases, total removal of $98.5 \%$ and 3 recurrent cases.

\section{References}

1- M. GAZI YASARGIL and S.I. ABDULRAUF: "Surgery of intraven-tricular tumors," Neurosurgery, Vol. 62, No. 6, pp. SHC1029-SHC1040, 2008.

2- R.T. GRONDIN, W. HADER, M.E. MacRAE and M.G HAMILTON: "Endoscopic versus microsurgical resection of third ventricle colloid cysts," Canadian Journal of Neurological Sciences, Vol. 34, No. 2, pp. 197-207, 2007.

3- M.S. ABDOUAND and A.R. COHEN: "Endoscopictreatmentofcolloid cysts of the third ventricle," Journal of Neurosurgery, Vol. 89, No. 6, pp. 1062-8, 1998.

4- A. GOEL: "Can the hype of, "Endoscope" become a reality for colloid cyst surgery?" World Neurosurg, No. 12, 2012.

5- B.D. MILLIGAN and F.B. MEYER: "Morbidity of transcallosal and transcortical approaches to lesions in and around the lateral and third ventricles: A single-institution experience," Neurosurgery, Vol. 67, No. 6, pp. 1483-96, 2010.

6- R.L. JEFFREEAND and M. BESSER: "Colloid cyst of the third ventricle: A clinical review of 39 cases," Journal of Clinical Neuroscience, Vol. 8, No. 4, pp. 328-3 1, 2001.

7- K.I. DESAI, T.D. NADKARNI, D.P. MUZUMDAR and A.H. GOEL: "Surgical management of colloid cyst of the third ventricle-a study of 105 cases," Surgical Neurology, Vol. 57, No. 5, pp. 295-302, 2002.

8- U. KEHLER, A. BRUNORI, J. GLIEMROTH, et al.: "Twenty colloid cysts-comparison of endoscopic and microsurgical management," Minimally Invasive Neurosurgery, Vol. 44, No. 3, pp. 121-7, 2001. 
9- J.P. LEJEUNE, D. Le GARS and E. HADDAD: "Tumors of the third ventricle: Review of 262 cases," Neurochirurgie, Vol. 46, No. 3, pp. 211-38, 2000.

10- A.I. LEWIS, K.R. CRONE, J. TAHA, H.R. VAN LOVEREN, H.S. YEH and J.M. TEW Jr.: "Surgical resection of third ventricle colloid cysts. Preliminary results comparing transcallosal microsurgery with endoscopy," Journal of Neurosurgery, Vol. 81, No. 2, pp. 174-8, 1994.

11- M.R. GAAB and H.W.S. SCHROEDER: "Neuroendoscopic approach to intraventricular lesions," Journal of Neurosurgery, Vol. 88, No. 3, pp. 496-505, 1998.

12- W.A. KING, J.S. ULLMAN, J.G. FRAZEE, K.D. POST and M. BERGSNEIDER: "Endoscopic resection of colloid cysts: Surgical considerations using the rigid endoscope," Neurosurgery, Vol. 44, No. 5, pp. 1103-11, 1999.

13- G.S. RODZIEWICZ, M.V. SMITH and C.J. HODGE Jr.: "Endoscopic colloid cyst surgery," Neurosurgery, Vol. 46, No. 3, pp. 655-62, 2000.

14- P. DECQ, C. Le GUERINEL, L. SAKKA, et al.: "Endoscopic surgery of third ventricle lesions," Neurochirurgie, Vol. 46, No. 3, pp. 286-94, 2000.

15- D. HELLWIG, B.L. BAUER, M. SCHULTE, et al.: "Neuroendoscopic treatment for colloid cysts of the third ventricle: The experience of a decade," Neurosurgery, Vol. 52, No. 3, pp. 525-33, 2003.

16- M. HUSAIN, D. JHA, D.K. VATSAL, et al.: "Neuroendoscopic surgery-experience and outcome analysis of 102 consecutive procedures in a busy neurosurgical center of India," Acta Neurochirurgica, Vol. 145, No. 5, pp. 36976, 2003.

17- P. LONGATTI, U. GODANO, M. GANGEMI, et al.: "Cooperative study by the Italian neuroendoscopy group on the treatment of 61 colloid cysts," Child's Nervous System, Vol. 22, No. 10, pp. 1263-7, 2006.

18- M.M. SOUWEIDANE and N. LUTHER: "Endoscopic resection of solid intraventricular brain tumors," Journal of Neurosurgery, Vol. 105, No. 2, pp. 271-8, 2006.

19- G.P. LEKOVIC, L.F. GONZALEZ, I. FEIZ-ERFAN and H.L. REKATE: "Endoscopic resection of hypothalamic hamartoma using a novel variable aspiration tissue resector," Neurosurgery, Vol. 58, No. 1, pp. S166-S8, 2006.

20- E.M. HORN, I. FEIZ-ERFAN, R.E. BRISTOL, et al.: "Treatment options for third ventricular colloid cysts: Comparison of open microsurgical versus endoscopic resection," Neurosurgery, Vol. 60, No. 4, pp. 613-8, 2007.

21- N.B. LEVINE, M.N. MILLER and K.R. CRONE:
"Endoscopic resection of colloid cysts: Indications, technique, and results during a 13-year period," Minim Invasive Neurosurg, Vol. 50, No. 6, Article ID 993215, pp. 313-7, 2007.

22- J.D.W. GREENLEE, C. TEO, A. GHAHREMAN and B KWOK: "Purely endoscopic resection of colloid cysts," Neurosurgery, Vol. 62, No. 3, pp. ONS51-ONS55, 2008.

23- N.M.F. EL-GHANDOUR: "Endoscopic treatment of third ven- tricular colloid cysts: A review including ten personal cases," Neurosurgical Review, Vol. 32, No. 4, pp. 395402, 2009.

24- J.M.K. OERTEL, J. BALDAUF, H.W.S. SCHROEDER and M.R. GAAB: "Endoscopic options in children: Experience with 134 procedures: Clinical article," Journal of Neurosurgery: Pediatrics, Vol. 3, No. 2, pp. 81-9, 2009.

25- S. MISHRA, S.P.S. CHANDRA, A. SURI, K. RAJENDER, B.S. SHARMA and A.K. MAHAPATRA: "Endoscopic management of third ventricular colloid cysts: Eight years' institutional experience and description of a new technique," Neurology India, Vol. 58, No. 3, pp. 412-7, 2010.

26- M.W. NAJJAR, N.I. AZZAM, T.S. BAGHDADI, A.H TURKMANI and G. SKAF: "Endoscopy in the management of intra-ventricular lesions: Preliminary experience in the Middle East," Clinical Neurology and Neurosurgery, Vol. 112, No. 1, pp. 17-22, 2010.

27- H.D. BOOGAARTS, P. DECQ, J.A. GROTENHUIS, et al.: "Long-term results of the neuroendoscopic management of colloid cysts of the third ventricle: A series of 90 cases," Neurosurgery, Vol. 68, No. 1, pp. 179-87, 2011.

28- R.P. NAFTEL, C.N. SHANNON, G.T. REED, et al.: "Small-ventricle neuroendoscopy for pediatric brain tumor management: Clinical article," Journal of Neurosurgery, Vol. 7, No. 1, pp. 104-10, 2011.

29- B.J. DLOUHY, N.S. DAHDALEH and J.D.W. GREENLEE: "Emerging technology in intracranial neuroendoscopy: Application of the NICO Myriad Technical note," Neurosurgical Focus, Vol. 30, No. 4, article E6, 2011.

30- A. DELITALA, A. BRUNORI and N. RUSSO: "Supraorbital endoscopic approach to colloid cysts," Neurosurgery, Vol. 69, No. 2, pp. 176-82, 2011.

31- D.A. WILSON, D.J. FUSCO, S.D. WAIT and P. NAKAJI: Endoscopic Resection of Colloid Cysts: Use of A DualInstrument Technique and an Anterolateral Approach, World Neurosurg., 2012.

32- K. MARGETIS and M.M. SOUWEIDANE: Endoscopic Treatment of Intraventricular Cystic Tumors, World Neurosurg, 2012. 


\section{الجراحات المنظّارية للبطين الثالث المحثى}

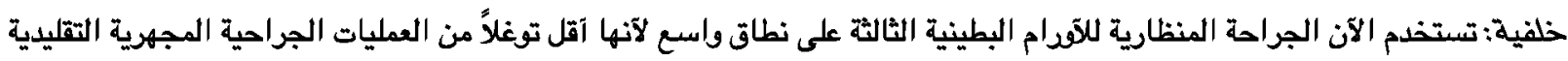

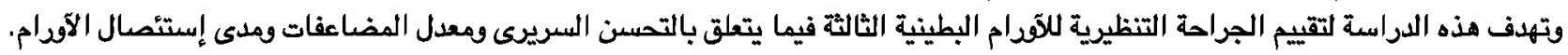

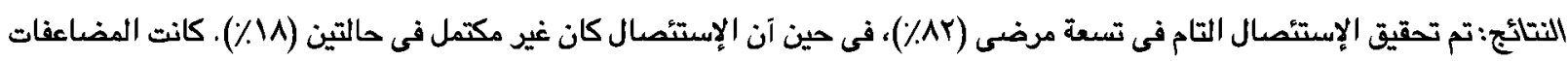

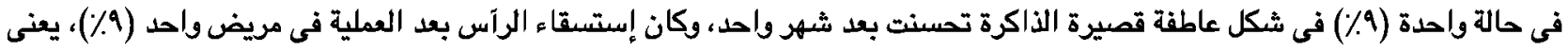

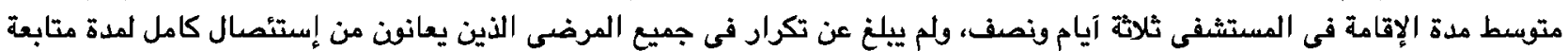
لمدة ri شهراً.

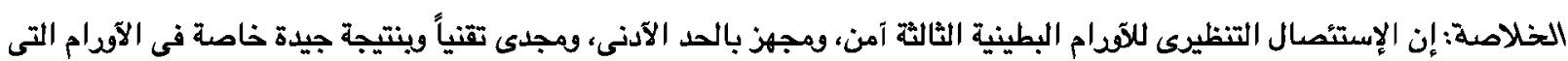

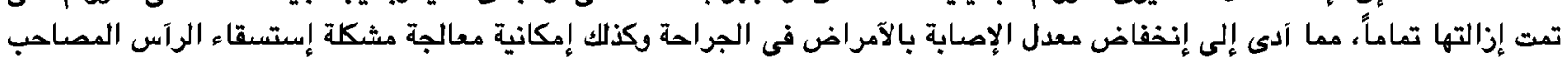

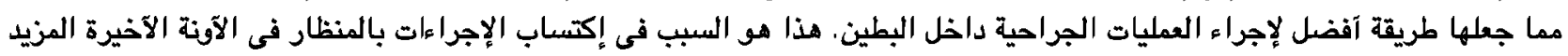
من الثعبية الجراحات داخل البطينات المخية. 